\title{
A Study of Compliance Based on Fault Analysis for Improving Reliability of Maintenance
}

\author{
Jang-Seop Song and Sung-Yul Rhew
}

\begin{abstract}
The quality management of software is very important. Especially, the cost of loss due to software defect is greatly huge. Based on the collection and analysis of defects as a measure of minimizing software defects, this study proposes creating defect classification and compliance regarding defect classification at the time of maintenance according to the defect classification. Software defects were collected by the defect classification, and the collected defect information was analyzed with symptom analysis, location analysis, cause analysis, and stage analysis. Defect compliance writes compliance details into the items of five classifications when maintaining and modifying programs with frequent errors. As a result of applying it to the defect tracking system of $W$ Company in order to verify the efficiency of the method that this study suggested, defects decreased approximately $29 \%$.
\end{abstract}

Index Terms-Software, maintenance, defect tracking, fault analysis, quality assurance, compliance.

\section{INTRODUCTION}

In IT operations organization, quality control of software maintenance stage is very important in order to increase the degree of satisfaction on user service. At maintenance stage, it requires efforts such as understanding and design of the program, test and verification, change management, and documentation [1]. Maintenance activity aims to stably operate a system by properly responding to the change of the hardware or operating system, discover, and improve errors or defects [2]. Especially, system failure that affects user service reduces the reliability of IT operations organizations, so defect management for preventing it in advance is necessary.

The purpose of defect management is minimizing defects, it belongs to reliability among six quality characteristics that are the ISO 9126 standards, and it belongs to compliance among the subcharacteristics of reliability [3]. This study provides information about compliance details of defects regarding the fact that there are many frequencies of occurrence in defect classification that is analyzed in maintenance and creates defect classification. Therefore, when improving systems in maintenance operation, it aims to reduce repetitive occurrence of defects and increase user reliability by providing compliance details regarding the fact that defects occur for many times.

Manuscript received July 8, 2013; revised September 16, 2013

Jang-Seop Song is with the Computer Science from Soongsil University, Seoul, Korea (e-mail: shoushou410@gmail.com).

\section{RELATED WORK}

\section{A. Maintenance Process and Required Man-Hour}

The method of maintenance shows huge difference according to the type of development of targeted work and individual's career, experience, or degree of understanding work. The results of estimating the degree of importance of process, error rate, and required man-hour by targeting forty companies with a maintenance-dedicated organization are like Table I [4].

TABLE I: MAINTENANCE PROCESS AND REQUIRED MAN-HOUR

\begin{tabular}{l|c|c|c}
\hline \hline Process & Importance & Error Rate & Man-Hour \\
\hline $\begin{array}{l}\text { Review the requirements } \\
\text { of the user }\end{array}$ & $2 \%$ & $12 \%$ & $5 \sim 8 \%$ \\
$\begin{array}{l}\text { Identify the scope of work } \\
\text { Schedule plans }\end{array}$ & $3 \%$ & $5 \%$ & $5 \sim 10 \%$ \\
$\begin{array}{l}\text { Schedule plans } \\
\text { Understanding of the S/W } \\
\text { system }\end{array}$ & $5 \%$ & $25 \%$ & $3 \sim 5 \%$ \\
$\begin{array}{l}\text { Coding } \\
\text { Understanding and }\end{array}$ & $15 \%$ & $8 \%$ & $10 \sim 20 \%$ \\
designing programs & $1 \%$ & $7 \%$ & $20 \sim 30 \%$ \\
Testing and Verification & $26 \%$ & $5 \%$ & $5 \sim 10 \%$ \\
Change Management and & $18 \%$ & $0 \%$ & $5 \sim 10 \%$ \\
Documentation & $2 \%$ & $6 \%$ & $5 \sim 8 \%$ \\
\hline \hline
\end{tabular}

In development process, it is stable when applying it for the first time to an operation environment because of sufficient work analysis, design, and test based on requirements by using methodology and tools. But in maintenance process, task requirements change often, and when a person, who did not participate in development at first, is put into maintenance, software defects occur often.

When program modification is inevitable due to task change, analyst and developer must be educated regarding user's work for clear understanding of the task change requirements and analysis [5]. If an error occurs after the change, cause and corrective measure should be recorded in the system, and when there are changes in a similar task or program, the past information should be traceable. Also, it is necessary to inspect abnormal effects due to change before actual change occurs [6].

\section{B. Defect Prediction Model}

The classification of reliability model of software is categorized like Table II according to application purpose and time [7].

According to the application purpose, it is like Fig. 1 [7], and the items are requirements, design, coding, unit test, integrated test, system test, acceptance test, and operation.

Late Defection Estimation tracks occurrence time 
information between defects by using information of defect that occurs from a test and predicts the future defect occurrence time through the information of defect occurrence time among the defects. The problem is utilizing data after the test, and the existing main SRE (Software Reliability Engineering) method is based on the defect data of the system occurred after the test stage.

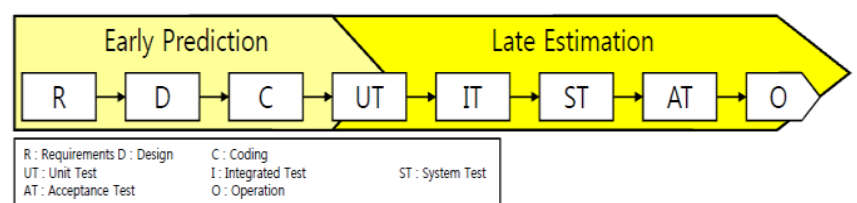

Fig. 1. Items according to the application purpose of a defect prediction model.

TABLE II: ApPliCATION PURPose AND TIME OF DEFECT PREDICTION MODEL

\begin{tabular}{|c|c|c|}
\hline Classification & Early Prediction & Late Estimation \\
\hline $\begin{array}{l}\text { Application } \\
\text { Purpose }\end{array}$ & $\begin{array}{l}\text { Predict defects from } \\
\text { the entire product at } \\
\text { the initial stage of the } \\
\text { project or defects for } \\
\text { each development } \\
\text { stage }\end{array}$ & $\begin{array}{l}\text { Estimate reliability of the } \\
\text { current system by using } \\
\text { defect data discovered from } \\
\text { the test or system operation }\end{array}$ \\
\hline $\begin{array}{l}\text { Application } \\
\text { Time }\end{array}$ & $\begin{array}{l}\text { Apply from the } \\
\text { beginning stage to the } \\
\text { development stage of } \\
\text { project }\end{array}$ & $\begin{array}{l}\text { Apply at the test stage of the } \\
\text { software system or the } \\
\text { operation stage }\end{array}$ \\
\hline Main Data & $\begin{array}{l}\text { - Information on the } \\
\text { history and } \\
\text { characteristics of the } \\
\text { defects from the past } \\
\text { projects } \\
\text { - Information on the } \\
\text { characteristics of the } \\
\text { current project }\end{array}$ & $\begin{array}{l}\text { - Information on the history } \\
\text { of defects from the past } \\
\text { projects } \\
\text { - Defect information } \\
\text { discovered from the current } \\
\text { project test or system } \\
\text { operation }\end{array}$ \\
\hline Main Model & $\begin{array}{l}\text { - Empirical Defect } \\
\text { Prediction Model } \\
\text { - COQUALMO } \\
\text { Model } \\
\text { - Phase Based } \\
\text { Prediction Model }\end{array}$ & $\begin{array}{l}\text { - Time dependent Model } \\
\text { - Time-independent Model }\end{array}$ \\
\hline
\end{tabular}

Therefore, it is a stage that is too late to change design in order to eliminate defects. Limits exist for collecting data of the system's defects. And the pros and cons of the Early Prediction Model are like Table III [7].

Most of software defects at the maintenance stage occur due to violating a very simple rule, and after discovering defects, the cause can be found within one hour and re-registered normally. Due to the errors that continue even during the defect restoration time, from simple errors to critical defect occur, and a management method of systematizing by integrating with software configuration management tool is necessary so that it can discover fundamental cause and prevent defect as much as possible [8].

\section{Creating Defect Classification Automatically}

Automatic defect classification provides defect report that is created automatically. Fig. 2 shows the outline of automatic defect classification [9].

Automatic defect classification consists of two important components. The basic classification system progresses in three steps like the following: first, pre-processing defect; second, ODC (Learning Orthogonal Defect Classification); third, classification step.

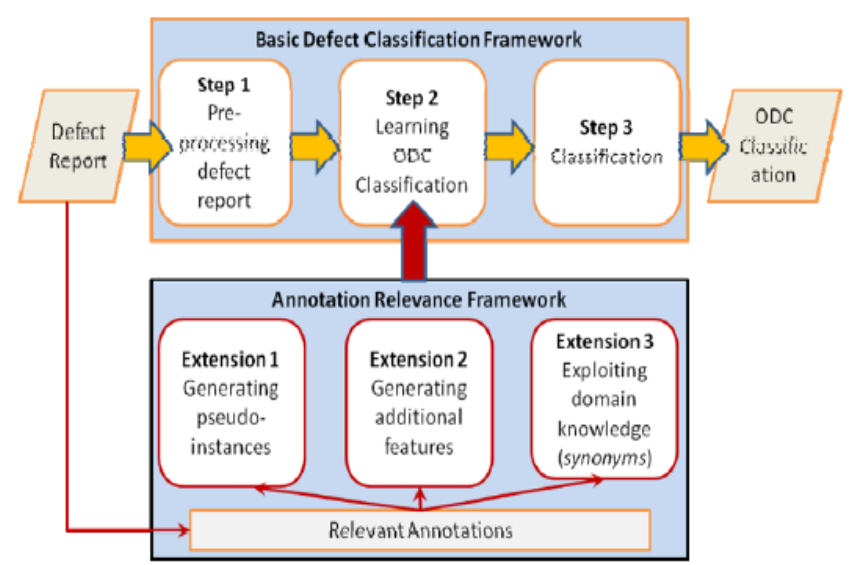

Fig. 2. Outline of automatic defect classification (autoODC).

TABLE III: PROS AND CONS OF EARLY PREDICTION MODEL

\begin{tabular}{|c|c|c|}
\hline $\begin{array}{l}\text { Prediction } \\
\text { Model }\end{array}$ & $\begin{array}{l}\text { Characteristics and } \\
\text { Merits }\end{array}$ & Things for Improvement \\
\hline $\begin{array}{l}\text { Empirical } \\
\text { Defect } \\
\text { Prediction }\end{array}$ & $\begin{array}{l}\text { - Easy to understand } \\
\text { and use the model } \\
\text { - Possible to realize. } \\
\text { though there is few } \\
\text { data. }\end{array}$ & $\begin{array}{l}\text { - Requires a process for } \\
\text { stabilized defect discovery } \\
\text { and standard SDLC } \\
\text { - Does not reflect proiect } \\
\text { characteristics and changed } \\
\text { details }\end{array}$ \\
\hline $\begin{array}{l}\text { COQUALM } \\
\mathrm{O}\end{array}$ & $\begin{array}{l}\text { - Predicts numbers of } \\
\text { defects in the stages of } \\
\text { requirement analysis, } \\
\text { design. and coding } \\
\text { - Considers effects } \\
\text { following the } \\
\text { characteristics of the } \\
\text { proiect (development } \\
\text { environment. products. } \\
\text { and personnel to } \\
\text { perform, and etc.) }\end{array}$ & $\begin{array}{l}\text { - Unable to predict defects } \\
\text { at the stage before the } \\
\text { proiect } \\
\text { - Does not provide defect } \\
\text { information after the text } \\
\text { stage and final delivery }\end{array}$ \\
\hline $\begin{array}{l}\text { Phase Based } \\
\text { Prediction }\end{array}$ & $\begin{array}{l}\text { - Provides numbers of } \\
\text { predicted defects for } \\
\text { each development } \\
\text { stage } \\
\text { - Possible to estimate } \\
\text { numbers of defect that } \\
\text { can be discovered at } \\
\text { the test stage }\end{array}$ & $\begin{array}{l}\text { - Absence of weight } \\
\text { according to the } \\
\text { characteristics of proiect } \\
\text { within the prediction model }\end{array}$ \\
\hline $\begin{array}{l}\text { Neural } \\
\text { Networks }\end{array}$ & $\begin{array}{l}\text { - Does not need a full } \\
\text { setting for project } \\
\text { situation } \\
\text { - Able to automatize } \\
\text { the construction of } \\
\text { prediction model }\end{array}$ & $\begin{array}{l}\text { - Impossible to interpret } \\
\text { studv result of the model } \\
\text { - Local minimum settlement } \\
\text { of the result values is } \\
\text { possible } \\
\text { - Needs the overall } \\
\text { re-learning at the time of } \\
\text { data addition }\end{array}$ \\
\hline $\begin{array}{l}\text { Bavesian } \\
\text { Belief } \\
\text { Networks }\end{array}$ & 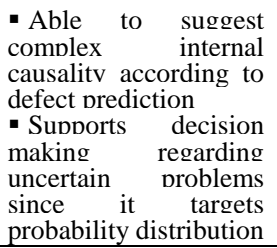 & $\begin{array}{l}\text { - Cannot guarantee } \\
\text { consistent result for } \\
\text { consecutive input value } \\
\text { - The invut value must be } \\
\text { within the prediction range } \\
\text { of the model (otherwise } \\
\text { abnormal error occurs) }\end{array}$ \\
\hline
\end{tabular}

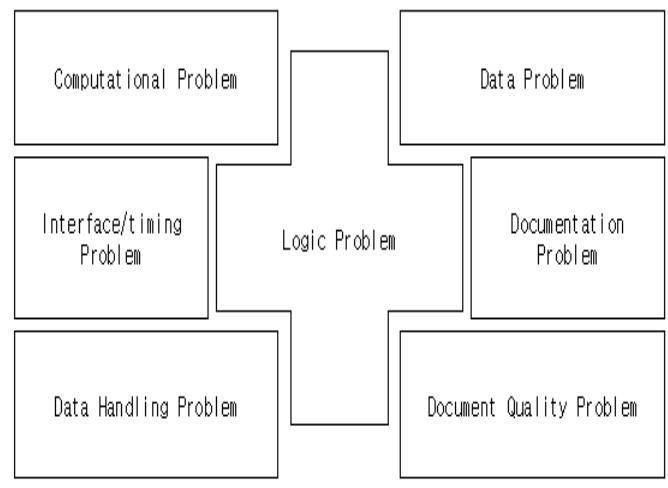

Fig. 3. Classification of software defect. 
Comment appropriateness framework has three ways: first, create pseudo-instance for SVM shunt training; second, create additional characteristics; third, add to the domain knowledge. And it is a frame work that extended the basic defect system utilizing comment [9].

\section{Classification of Software Defects}

Classification of software defects is composed of seven parts, and it is like Fig. 3. that shows logic problems, computational problems, interface/timing problems, data handling problems, data problems, documentation problems, and document quality problems.

\section{Compliance Details of Defect Classification AND DESIGN OF CREATING DEFECT ClaSSIFICATION}

\section{A. Data Collection and Defect Classification}

Use a configuration management system for collecting defect prediction data. Analyze the registration due to errors in the past year and select seven classifications that are the most frequent. This study collects data and analyzes defect classification regarding three banks' financial information systems. Table IV shows software defect classification.

TABLE IV: CLASSIFICATION OF SOFTWARE DEFECT

\begin{tabular}{ll} 
Classification & Classification of defect \\
\hline Classification 1 & Logic Problem \\
Classification 2 & Calculating Problem \\
Classification 3 & Interface \& Timing Problem \\
Classification 4 & Data control Problem \\
Classification 5 & Data Problem \\
Classification 6 & Documentation Problem \\
Classification 7 & Documentation Quality Problem \\
\hline \hline
\end{tabular}

\section{B. Defect Analysis Techniques}

Analysis techniques according to defect classification are symptom analysis, location analysis, cause analysis, and stage analysis.

Symptom analysis is an effect regarding software defect, indicating clash of the operation system, program freeze and clash, input error, output error, failure of the required functions, overall failure of the product, system error message, and others. Location analysis is the place where a defect occurred, and there are $\mathrm{S} / \mathrm{W}, \mathrm{DB}, \mathrm{H} / \mathrm{W}$, and external.

Cause analysis is direct cause of defect occurrence, and there are logic error, computational error, interface/timing error, data handling error, data error, documentation error, and document quality error. Stage analysis is classified as software development life cycle, and there are definition of user requirements, requirements analysis, architecture design, $\mathrm{S} / \mathrm{W}$ detail design, realization, $\mathrm{S} / \mathrm{W}$ integration, $\mathrm{S} / \mathrm{W}$ integration test, system integration, system test, change, acceptance test, operation, maintenance, and others.

As the result of analyzing the types of errors that occurred the most in the past, logic errors and data errors happened $43 \%$ of the entire error, and Fig. 4 shows the error ratio with the software defect classification.

When subdividing the logic errors that occupy $35 \%$, which is the result of analyzing defect classification, it can be classified into the errors of Forgotten cases or steps, Duplicate logic, Extreme conditions neglected, Unnecessary function, Misinterpretation, Missing condition test, Checking wrong variable, and Integrating loop incorrectly.

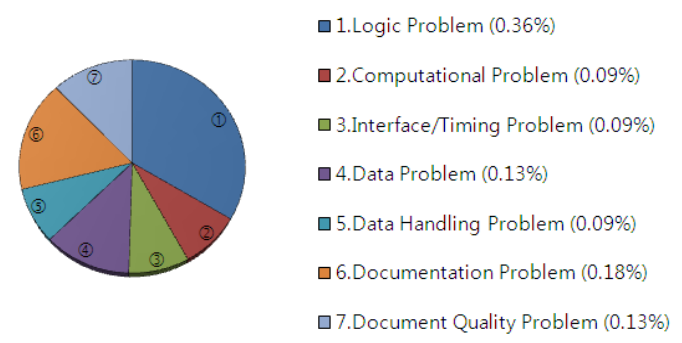

Fig. 4. Classification ratio of software defects.

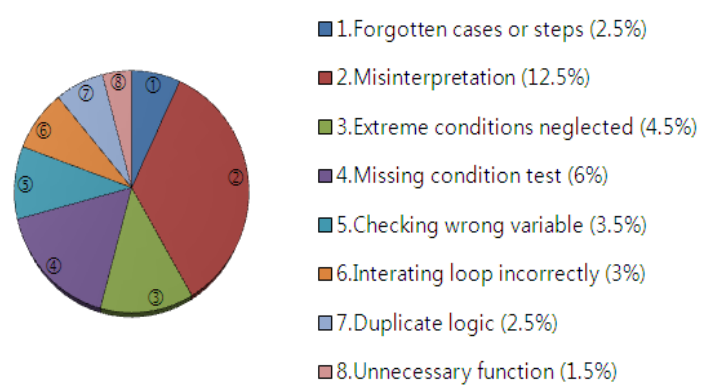

Fig. 5. Ratio per type of errors regarding logic.

They show ratio per type of errors regarding logic. When suggesting a compliance item for logic error, the ratio for defects decreases. (see Fig. 5).

\section{Framework that Creates Defect Classification}

The framework for creating defect classification in a defect tracking system is composed of four steps like Fig. 6. Step 1 is based on defect report generated from unit test and integration test of the project, and it maps error vs. defect classification at Step 2. And Step 3 adds newly-added defects through the system error log that occurs at the maintenance stage to mapping information. Step 4 shows defect classification.

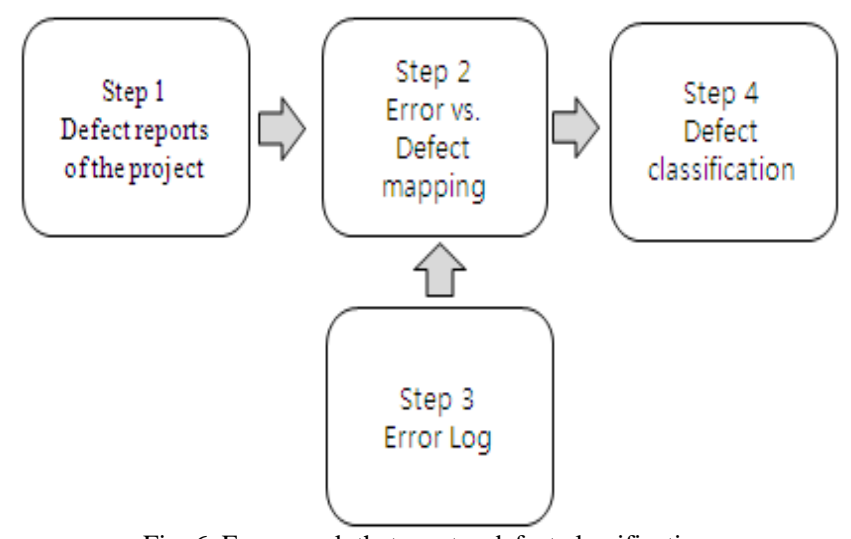

Fig. 6. Framework that creates defect classification.

The summary sheet per error type of the program is inquired only when there is at least one copy of the program defect of three teams. In Fig. 7, Team 1 registered 750 copies of the program, there are 8 copies of the program that had logic errors, and its defect ratio is $1.06 \%$. Team 2 registered 600 copies, there are 3 copies of the program with logic errors, and its defect ratio is $0.5 \%$. 
Team 3 registered 850 copies and has 7 copies of the program that had logic errors, and its defect ratio is $0.82 \%$. The total of 2,200 copies of the program is the number of the registered program copies of the organization, and it is calculated by including the team with no defect in order to estimate the overall defect ratio of the organization. There were defects in the total of 24 copies of the program, and the overall defect ratio of the organization is $1.09 \%$. Table $\mathrm{V}$ is the summary sheet of software defect classification.

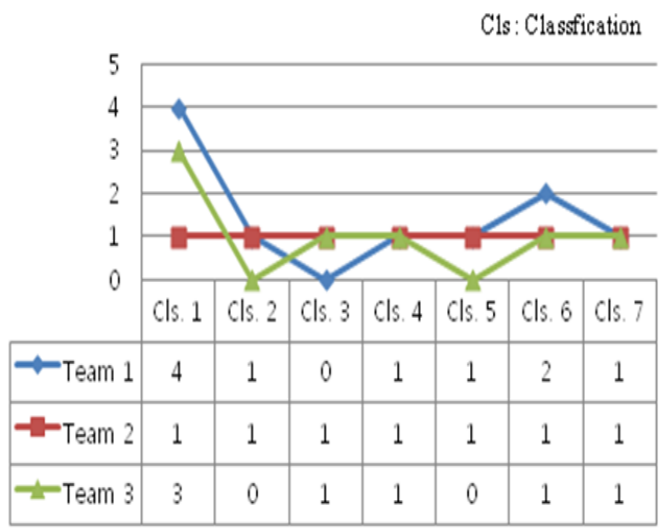

Fig. 7. Aggregate of program errors classification.

TABLE V: CLASSIFICATION OF SOFTWARE DEFECTS AND TEAM AGGREGATE

\begin{tabular}{lllll}
\hline \hline Classification & Team 1 & Team 1 & Team 1 & Total \\
\hline Cls1 & 4 & 1 & 3 & $8(0.36)$ \\
Cls2 & 1 & 1 & 0 & $2(0.09)$ \\
Cls3 & 0 & 1 & 1 & $2(0.09)$ \\
Cls4 & 1 & 1 & 1 & $3(0.13)$ \\
Cls5 & 1 & 1 & 0 & $2(0.09)$ \\
Cls6 & 2 & 1 & 1 & $4(0.18)$ \\
Cls7 & 1 & 1 & 1 & $3(0.13)$ \\
Total & $10 / 750$ & $7 / 600$ & $7 / 850$ & $24 / 2,200$ \\
\hline \hline
\end{tabular}

\section{Designing Compliance Details for Defect Classification}

Manage the program list with high frequency of defects, and write items for compliance details so that the defects in the past would not occur again. Table VI shows a program defect list.

TABLE VI: PROGRAM DEFECT LIST

\begin{tabular}{lllll}
\hline \hline No. & Program & Registration & Defect & Defect rates \\
\hline 1 & Program 1 & 5 & 3 & $60 \%$ \\
2 & Program 2 & 6 & 3 & $50 \%$ \\
3 & Program 3 & 16 & 7 & $44 \%$ \\
4 & Program 4 & 7 & 3 & $43 \%$ \\
5 & Program 5 & 12 & 5 & $42 \%$ \\
6 & Program 6 & 10 & 4 & $40 \%$ \\
7 & Program 7 & 8 & 3 & $40 \%$ \\
8 & Program 8 & 12 & 3 & $25 \%$ \\
9 & Program 9 & 25 & 6 & $24 \%$ \\
10 & Program 10 & 13 & 3 & $20 \%$ \\
\hline \hline
\end{tabular}

The person in charge of quality assurance of program checks frequent defects per business department from the defect tracking system and provides them to the relevant business department like Table VII. When registering a program, a business department is to check confirmation and attach as product. The checklist consists of the items for checking regarding cases per error type. By doing so, developer can inspect in advance so that errors that were repeated in the past would not occur again.
TABLE VII: COMPLIANCE ITEMS FOR DEFECT CLASSIFICATION

\begin{tabular}{|c|c|}
\hline Classification. & Compliance items \\
\hline \multirow{12}{*}{ Logic } & Forgotten cases or steps \\
\hline & Duplicate logic \\
\hline & Extreme conditions neglected \\
\hline & Unnecessary function \\
\hline & Misinterpretation \\
\hline & Missing condition test \\
\hline & Checking wrong variable \\
\hline & Iterating loop incorrectly \\
\hline & Equation insufficient or incorrect \\
\hline & Missing computation \\
\hline & Operand in equation incorrect \\
\hline & Operator in equation incorrect \\
\hline \multirow[t]{9}{*}{ Computational } & Parentheses used incorrectly \\
\hline & Precision loss \\
\hline & Rounding or truncation fault \\
\hline & Mixed modes \\
\hline & Sign convention fault \\
\hline & Initialized data incorrectly \\
\hline & Accessed or stored data incorrectly \\
\hline & Flag or index set incorrectly \\
\hline & Packed/unpacked data incorrectly \\
\hline \multirow{10}{*}{$\begin{array}{c}\text { Data } \\
\text { Handling }\end{array}$} & Referenced wrong data variable \\
\hline & Data referenced out of bound \\
\hline & Scaling or units of data incorrect \\
\hline & Dimensioned data incorrectly \\
\hline & Variable type incorrect \\
\hline & Subscripted variable incorrectly \\
\hline & Scope of data incorrect \\
\hline & Sensor data incorrect or missing \\
\hline & Operator data incorrect or missing \\
\hline & $\begin{array}{l}\text { Embedded data in tables incorrect or } \\
\text { missing }\end{array}$ \\
\hline \multirow{7}{*}{ Data } & External data incorrect or missing \\
\hline & Output data incorrect or missing \\
\hline & Input data incorrect or missing \\
\hline & Ambiguous statement \\
\hline & Incomplete item \\
\hline & Incorrect item \\
\hline & Missing item \\
\hline \multirow{8}{*}{ Documentation } & Conflicting item \\
\hline & Redundant item \\
\hline & Confusing item \\
\hline & Illogical item \\
\hline & Non-verifiable item \\
\hline & Unachievable item \\
\hline & Applicable standards not met \\
\hline & Not traceable \\
\hline \multirow{4}{*}{$\begin{array}{l}\text { Documentation } \\
\text { Quality }\end{array}$} & Not current \\
\hline & Inconsistencies \\
\hline & Incomplete \\
\hline & No identification \\
\hline
\end{tabular}

\section{VERIFICATION AND TEST}

\section{A. Analysis and Measurement for Defect Classification of Program}

Collecting and analyzing defects are preparation process for improvement. A defect tracking system stores information related to error types of the collected contents and provides service. The quality control department of an organization create index for managing defects, notify the business department regarding the measurement result such as the average defect ratio of the defect tracking system and the average defect delay time, and lead improvement. In other words, the quality control department plays a role of managing and controlling to improve the quality of an 
organization.

For a business department with more than $0.621 \%$ of the defect ratio that is 4 sigma level, request to find cause and improve by checking error type and related program from the defect tracking system. The measurement index is like Table VIII. There are number of program defects discovered from test stage (pd), number of program registration (pr), time of defect occurrence (pt1), time for defect restoration ( $\mathrm{pt} 2)$, program unit (i), and number of the overall program (n).

TABLE VIII: MEASUREMENT INDEX [10]

\begin{tabular}{ll}
\hline \hline Index & Expression \\
\hline Average defect rate & $\sum_{i=1}^{n}((p d / p r) * 100)_{i} / \mathrm{n}$ \\
Average latency of & $\sum_{i=1}^{n}(p t 2-p t 1)_{i} / \mathrm{n}$ \\
defect & \\
\hline
\end{tabular}

\section{B. Result of Measuring Defect Classification of Program}

The study for predicting and minimizing defects targets approximately 600,000 copies of a program that is registered in the program configuration management system. It collected the history of the changes of the program and classified the defects that occurred in the past. And it strengthened test or inspection according to the past history by predicting the possibility of defect occurrence before registering a program through the history of defect and linked program tracking. After applying the method that this study suggests, it verifies whether or not defect ratio decreased.

It materializes a defect tracking system through deducing requirements for defect tracking and effect analysis. It collects defect prediction data by using a program configuration management system, analyzes program error type, and conducts measurement. It systematically managed defects in the program with the defect tracking process and considered the program that wanted to change through program influence analysis and program that can have indirect influences. Also, it decreases the overall defects by focusing on the management of the department that has tasks or programs with many defects through an organization's quality control activity.

TABLE IX: RESUlt OF THE MEASURING DEFECT RATIO

\begin{tabular}{lllll}
\hline \hline No. & Program & Registration & Defect & Defect rates \\
\hline 1 & Program 1 & 5 & 3 & $60 \%$ \\
2 & Program 2 & 6 & 3 & $50 \%$ \\
3 & Program 3 & 16 & 7 & $44 \%$ \\
4 & Program 4 & 7 & 3 & $43 \%$ \\
5 & Program 5 & 12 & 5 & $42 \%$ \\
6 & Program 6 & 10 & 4 & $40 \%$ \\
7 & Program 7 & 8 & 3 & $40 \%$ \\
8 & Program 8 & 12 & 3 & $25 \%$ \\
9 & Program 9 & 25 & 6 & $24 \%$ \\
10 & Program 10 & 13 & 3 & $20 \%$ \\
\hline \hline
\end{tabular}

To verify the result of performing defect improving activity by utilizing a defect tracking system, it performed a test that measured and compared the average defect ratio of the recent six months and six months before that. The defect ratio of the six months before performing the defect tracking and improving activity by using a defect tracking system was approximately $0.59 \%$, and approximately $0.27 \%$ for the six months after the performance, thus improving approximately $29 \%$. The result of the measuring defect ratio is like Table IX, and the result of the improving defect ratio is like Fig. 8 .

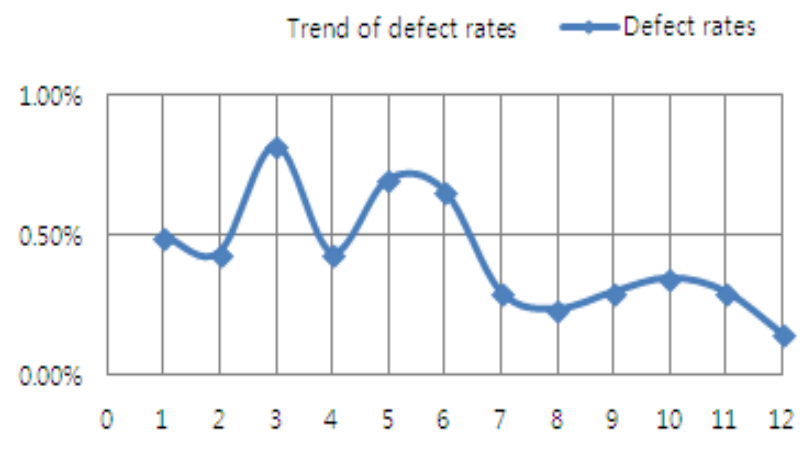

Fig. 8. Result of the measuring defect ratio.

\section{CONCLUSION AND Future STUdy}

This study suggested a method that minimizes the defects of software by using the information after the system manages the defect information and measures the collected data when a defect occurs due to the change of the program in the operation environment of maintenance after development. According to the Pareto' s Law, program error or defect occurrence of an organization are focused on a certain organization and certain task developer. In other words, the principle that the type that already occurred occurs repetitively and takes up the most of the overall defects could be found.

In order to eliminate repetitive defects with such concept as foundation, find defect classification of an organization, which occurs often, while examining its progress based on a defect tracking system. Afterwards, continuously measure defect classification and give feedbacks to the person who is in charge of the related task in an organization from the improvement aspect. Also, the person in charge of an organization's quality should write compliance details regarding the causes that occurred frequently by analyzing program errors or defects of the configuration management system per type and distribute to the related department, and when there is new defect classification, add it to the classification mapping information.

For a defect tracking system, analyze the department where defects occur frequently or the program with high frequency of defects regarding software that the person in charge manages, improve defect information, and support so that they can inspect and check one more time. Since it analyzed the cause of program defect, which was suitable for the job characteristics of an organization, and provided information on defect compliance details, it reduced maintenance cost after defects occurred. And it was able to increase the degree of satisfaction of customers or users by securing reliability of software. If the maintenance of organization is improved continuously with such method, it would secure operation productivity of maintenance and work environment.

In other words, it analyzes the accumulation of rework time according to defect per team due to the accumulation of defect data and rework time of defect data, establishes rework time standards for classification by defect classification, and 
estimates practical program development productivity. When estimating development man-hour for program, it reflects defect prediction and required rework time factor. It economizes unnecessary defect modification time, and the maturity of software improves since customer reliability increases.

This study uses a semi-automatic mapping table for creating defect classification as a limit point. It requires studies on the method of creating defect classification automatically.

\section{REFERENCES}

[1] S/W Development Process to Improve the Capability Maturity Model, Carnegie Mellon University, Pearson edu korea, 2002.

[2] P. Grubb and A. A Takang, "Software Maintenance Concepts and Practice," World Scientific, 2003.

[3] ISO/IEC 9126, "Infomation Technology," Software Quality Characteristics and Metrics, Part 1, 2, 3 .

[4] S. Y. Rhew, B. K. Seop, and H. Kim, "A study on the formalization of maintenance management systems and the cost predictive mode," Korea Information Processing Society, vol. 3, no. 4, pp. 846-854, 1996.

[5] K. E. Wiegers, Software Requirements, JungBo Publisher, 2003

[6] E. M. Choi, Software Engineering, JungIkSa Publisher, 2007

[7] H. Y. Kim and H. S. Han, "SW-FMEA based on the model of the defect prevention," Korean Institute of information Scientists and Engineers, 605-614, 2006
[8] M. B. Doar, Practical Development Environments, O'Reilly \& Associates, 2005.

[9] L. G. Huang, V. Ng, I. Persing, R. 1. Geng, X. Bai, and J. Tian "Autoodc: automated generation of orthogonal defect classifications," in Proc. 26 $6^{\text {th }}, 2011$ IEEE/ACM International Conference, pp. 412-415, 2011.

[10] Y. J. Mun, "A fault and replacement time prediction technique to improve it service reliablility," Soongsil University, pp. 32, 2013.

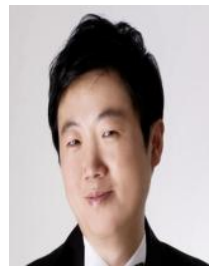

Jang Seop Song received the MS and BS degrees in computer science from Soongsil University, Seoul, Korea, in 2007 and 2000, respectively. He is Ph.D Candidate at SoongSil University, Korea. $\mathrm{He}$ is working as a IT Manager, Korea. His current research interests include software maintenance, internet ethics.

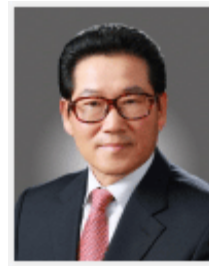

Sung Yul Rhew received the $\mathrm{Ph} . \mathrm{D}$ degree in computer science from Ajou University and the MS degrees in computer science from Yonsei University, Seoul, Korea, in 1996 and 1980, respectively. He is working as a professor of software engineering in school of computer science and engineering at the Soongsil University. His research interests include software requirement engineering, software maintenance, open 